\title{
PENGARUH SIMPANAN BERJANGKA TERHADAP DANA BAITUL MAAL SEBAGAI IMPLEMENTASI COORPORATE SOCIAL RESPONSIBILITY DI KJKS BMT UMAT SEJAHTERA TAHUN 2014
}

\author{
Wenny Marlini \\ Program Studi Akuntansi, Politeknik Dharma Patria Kebumen \\ wewenlin3832@gmail.com
}

Inas Luthfiana 12.301 .069

\begin{abstract}
ABSTRAK
Perkembangan Lembaga Keuangan Syariah di Indonesia sangat pesat, akan tetapi kesadaran bahwa eksistensi perusahaan akan mampu bertahan jika perusahaan mampu memberikan pengembalian terhadap masyarakat membuat lembaga keuangan yang bermunculan semakin beranekaragam. KJKS BMT Umat Sejahtera merupakan salah satu lembaga keuangan berbasis koperasi syariah di Kabupaten Kebumen yang kegiatannya diimbangi dengan kegiatan sosial Baitul Maal sebagai Corporate Social Responsibility perusahaan. Salah satu produk unggulan adalah simpanan berjangka dimana setiap simpanan berjangka akan dikenai ziswaf sebagai penghimpun dana Baitul Maal.

Pada tugas akhir ini penelitian dilakukan bertujuan mengetahui pengaruh simpanan berjangka terhadap dana Baitul Maal sebagai implementasi Corporate Social Responsibility di KJKS BMT Umat Sejahtera.

Metode penelitian yang digunakan adalah deskriptif. Sumber data dalam penelitian ini diambil dari laporan rapat akhir tahun serta dokumen lain yang berhubungan dengan penelitian. Penelitian ini menggunakan uji regresi linier sederhana. Hasil penelitian ini menunjukan terdapat pengaruh signifikan antara simpanan berjangka dengan dana Baitul Maal sebagai implementasi Corporate Social Responsibility di KJKS BMT Umat Sejahtera, dibuktikan dengan $t$ hitung simpanan berjangka $(2,449)$ lebih besar dari t tabel $(2,22814)$. Besaran pengaruh adalah $40 \%$ sedangkan $60 \%$ dipengaruhi oleh faktor lain.

Dari hasil tersebut perlu adanya pengoptimalan dari produk lain yang dimiliki BMT, misalnya dengan mengintensifkan promosi produk pembiayaan dan simpanan lain untuk memaksimalkan penghimpunan dana Corporate Social Responsibility perusahaan.
\end{abstract}

KataKunci : Simpanan Berjangka, Baitul Maal, Coorporate Social Responsibility (CSR).

\section{ABSTRACT}

The development of Islamic Financial Institutions in Indonesia is very rapid, but the awareness that the existence of the company will be able to survive if the company is able to provide a return to the community to make the financial institutions are popping up more and more diverse.KJKS BMT Umat Sejahtera is one of financial institutions the cooperative based syariah in Kebumen that syariah cooperative is also balanced with social activities Baitul Maal as Corporate Social Responsibility companies. One of the flagship products are deposits which each deposits will be charged ziswaf as collector of Baitul Maal funds.

In this final study was conducted to determine the effect of deposits to Baitul Maal fund as the implementation of Corporate Social Responsibility in KJKS BMT Umat Sejahtera.

The research method used was descriptive. Sources of file in this study were taken from the end of the meeting reports and other documents related to the study. This study used a simple linear regression. These results indicated there was significant influence between deposits with the Baitul Maal fund as the implementation of Corporate Social Responsibility in KJKS BMT Umat Sejahtera, it was evidenced by the time deposits $(2,449)$ was greater than t table (2.22814). The effect was $40 \%$ and $60 \%$ another factor.

From these results the need for optimization of other products BMT's have, for example by intensifying the promotion of savings and other financial products in order to maximize of Corporate Social Responsibility fund.

Keywords : Deposits, Baitul Maal, Corporate Social Responsibility (CSR). 


\section{A. PENDAHULUAN}

\section{Latar Belakang Masalah}

Perkembangan lembaga keuangan syariah di Indonesia dimulai semenjak tahun 1990-an dan mengalami perkembangan yang semakin marak pada awal tahun 2000-an. Ditandai dengan bermunculannya sejumlah bank syariah yang didirikan oleh perbankan konvesional, baik yang sahamnya dimiliki pemerintah maupun swasta. Salah satu lembaga keuangan syariah yang sedang berkembang yaitu Baitul Maal Wat Tamwil atau lebih dikenal dengan BMT adalah institusi keuangan yang berbasis syariah Islam. Hal ini berarti bahwa secara makro BMT adalah institusi keuangan yang memposisikan dirinya sebagai pemain aktif dalam mendukung dan memainkan kegiatan investasi di masyarakat sekitarnya sesuai dengan aturan dan syariat Islam.

Tanggung jawab sosial perusahaan adalah tanggung jawab terhadap masyarakat di luar tanggung jawab ekonomis. Jika kita berbicara tentang tanggung jawab sosial perusahaan, maksudnya adalah kegiatan - kegiatan yang dilakukan perusahaan demi suatu tujuan sosial dengan tidak memperhitungkan untung atau rugi ekonomis. Seiring dengan makin kompleksnya kepemilikan sebuah usaha, konsep Corporate Social Responsibility sebagai tanggung jawab sebuah perusahaan menjadi meluas maknanya, salah satunya adalah niat baik dan komitmen dari perusahaan untuk memberikan kontribusi terhadap peningkatan kualitas hidup masyarakat, keberlanjutan pengembangan masyarakat dan ekonomi lokal sehingga memberikan kontribusi juga terhadap keberlanjutan perusahaan. Dalam hal ini, Corporate Social Responsibility di Baitul Maal Wat Tamwil sudah ada sejak berdirinya lembaga keuangan tersebut. Dibuktikan dengan keberadaan BMT sebagai Koperasi Jasa Keuangan Syariah yang selalu diimbangi dengan Baitul Maal yang menghimpun dana zakat, infak dan shodakoh dari para nasabah sekaligus sebagai donatur untuk kemudian disalurkan kembali kepada yang berhak. Tidak hanya dari para donatur, peran nasabah juga sangat penting dalam penghimpunan dana Corporate Social Responsibility tersebut, dikarenakan setiap simpanan yang dititipkan di BMT akan dikenai zakat atau donasi lain sesuai nisbahnya.

Hal inilah yang mendorong peneliti untuk melakukan penelitian di KJKS BMT Umat Sejahtera mengenai salah satu produknya yaitu produk simpanan, khususnya Simpanan Berjangka. Dimana saat ini KJKS BMT Umat Sejahtera merupakan koperasi terbaik di Kabupaten Kebumen dengan aset mencapai 22,5 M. Oleh karena itu fokus bahasan pada tulisan ini akan membahas khusus tentang Pengaruh
Simpanan Berjangka untuk selanjutnya dalam penelitian ini akan peneliti kaitkan dengan dana Baitul Maal sebagai implementasi Coorporate Social Responsibility di KJKS BMT Umat Sejahtera tahun 2014.

\section{Pokok Permasalahan}

Dalam penelitian ini penulis akan membahas tentang bagaimana pengaruh simpanan berjangka terhadap dana Baitul Maal sebagai implementasi Corporate Social Responsibility di KJKS BMT Umat Sejahtera tahun 2014?

\section{Pertanyaan Penelitian}

1. Bagaimana kondisi Simpanan Berjangka di KJKS BMT Umat Sejahtera tahun 2014?

2. Bagaimana pelaksanaan Baitul Maal sebagai Corporate Social Responsibility di KJKS BMT Umat Sejahtera?

3. Bagaimana pengaruh simpanan berjangka terhadap dana Baitul Maal sebagai implementasi Coorporate Social Responsibility di KJKS BMT Umat Sejahtera?

\section{Tujuan Penelitian}

1. Untuk mengetahui kondisi simpanan berjangka di KJKS BMT Umat Sejahtera tahun 2014.

2. Untuk mengetahui bagaimana pelaksanaan Baitul Maal sebagai Corporate Social Responsibility di KJKS BMT Umat Sejahtera.

3. Untuk mengetahui pengaruh simpanan berjangka terhadap dana Baitul Maal sebagai Implementasi Corporate Social Responsibility di KJKS BMT Umat Sejahtera.

\section{B. KERANGKA PEMIKIRAN DAN METODE PENELITIAN \\ Kajian Ilmiah}

Simapanan berjangka atau dalam perbankan disebut dengan deposito didefinisikan sebagai simpanan yang penarikannya hanya dapat dilakukan pada waktu tertentu berdasarkan perjanjian pemilik dana dengan bank atau lembaga keuangan lain atau pada saat jatuh tempo (Undang - Undang Nomor 10 tahun 1998). Sedangkan dalam Pasal 1 angka 22 Undang - Undang Nomor 21 Tahun 2008, Deposito didefinisikan sebagai Investasi dana berdasarkan Akad Mudharabah atau Akad lain yang tidak bertentangan dengan prinsip syariah yang penarikannya hanya dapat dilakukan pada waktu tertentu berdasarkan akad antara nasabah penyimpan dengan Lembaga Keuangan Syariah

Defenisi Corporate Social Responsibilityadalah "kepedulian perusahaan yang menyisihkan sebagian keuntungannya (profit) bagi kepentinganpembangunan manusia dan 
lingkungan secara berkelanjutan berdasarkan proseduryang tepat dan profesional" (Bambang Rudito \& Melia Famiola 2007:220).

Sedangkan dilihat dari sisi etimologiCorporate Social Responsibility kerap diterjemahan sebagai“Tanggung jawab sosial perusahaan atau tanggung jawab sosial korporasi atautanggung jawab sosial dunia usaha. Yusuf Wibisono mendefinisakan Corporate Social Responsibility sebagaitanggung jawab perusahaan kepada para pemangku kepentingan untuk berlaku etis, meminimalkan dampak negatif dan memaksimalkan dampak positif yangmencakup aspek sosial dan lingkungan (triple bottom line) dalam rangkamencapai tujuan pembangunan berkelanjutan (2007:7).

Baitul Maal merupakan lembaga penghimpun dana zakat, infak, shodaqoh dan wakaf untuk kemudian ditasarufkan kembali kepada pihak yang membutuhkan. Sedangkan Corporate Social Responsibility merupakan tanggung jawab perusahaan kepada para pemangku kepentingan untuk berlakuetis, meminimalkan dampak negatif dan memaksimalkan dampak positif yangmencakup aspek sosial dan lingkungan (triple bottom line) dalam rangkamencapai tujuan pembangunan berkelanjutan

\section{Kerangka Pemikiran}

Adapun kerangka pikir yang digunakan dalam penelitian ini adalah sebagai berikut tampak pada gambar di bawah ini:

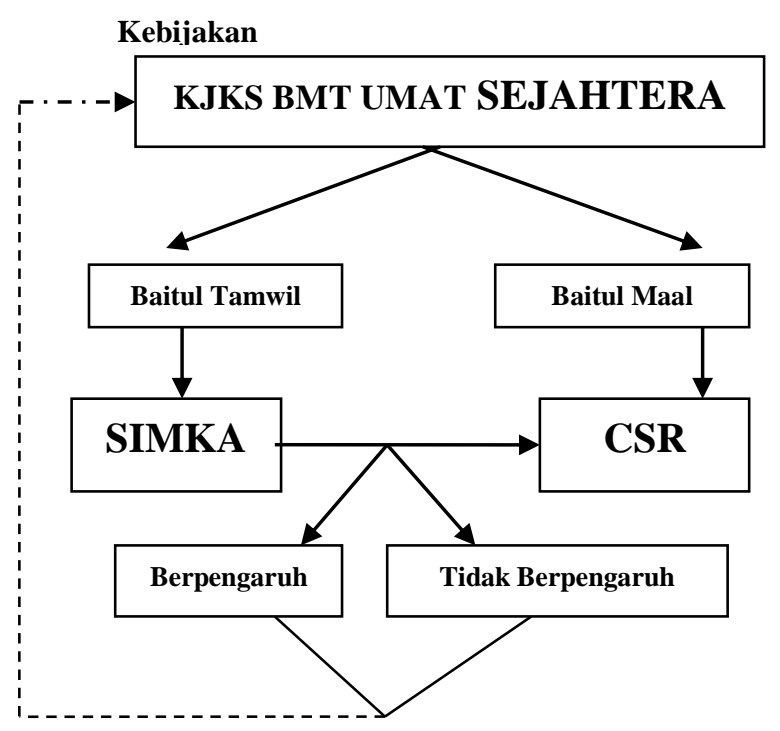

Metode Penelitian

\section{A. Tempat dan Waktu Penelitian}

Metode Penelitian yang penulis gunakan dalam penelitian ini adalah dengan menggunakan metode deskriptif analisis dengan pendekatan kuantitatif merupakan metode yang bertujuan menggambarkan benar tidaknya fakta - fakta yang ada serta menjelaskan tentang hubungan antara variable yang diselediki dengan cara mengumpulkan data, mengolah, menganalisis dan menginterprestasi data dalam pengujian hipotesis statistik. Metode penelitian ini bertujuan menguji lebih dalam pengaruh simpanan berjangka dan dana Corporate Social Responsibility dengan membandingkan variable dependen dengan variable independen.

Berdasarkan dari tujuan penelitian, maka variabel yang dianalisis adalah; Simpnan Berjangka sebagai variabel bebas atau dependen (X) serta Dana Baitul Maal sebagai variabel yang terikat atau independen (Y). Sumber primer adalah sumber data yang langsung memberikan data kepada pengumpul data dan sumber sekunder merupakan sumber yang tidak langsung kepada pengumpul data, misalnya lewat orang lain atau lewat dokumen (Sugiyo, 2012:187).

Data dalam penelitian ini termasuk ke dalam jenis data sekunder dengan sumber primer karena sumber data langsung memberikan data kepada pengumpul data.

\section{B. Jenis Penelitian}

Sumber primer adalah sumber data yang langsung memberikan data kepada pengumpul data dan sumber sekunder merupakan sumber yang tidak langsung kepada pengumpul data, misalnya lewat orang lain atau lewat dokumen (Sugiyo, 2012:187).

Data dalam penelitian ini termasuk ke dalam jenis data sekunder dengan sumber primer karena sumber data langsung memberikan data kepada pengumpul data.

\section{Variabel Penelitian}

Dalam penelitian ini terdapat 2 (dua) jenis variabel, yaitu:

a. Variabel bebas (independent variable), yaitu variabel yang menjadi sebab timbulnya atau berubahnya variabel terikat (dependent variable), dengan kata lain variabel yang mempengaruhi (Sugiyono, 2012: 3). Dalam penelitian ini, variabel bebasnya adalah

Simpanan Berjangka $(\mathrm{X})$

b. Variabel terikat (dependent variable), yaitu variabel yang dipengaruhi atau yang menjadi akibat karena adanya variabel bebas (Sugiyono, 2012: 3). Dalam penelitian ini variabel terikatnya adalah Dana Baitul Maal (Y). 


\section{Definisi Operasional Variabel}

Operasionalisasi variabel pada dasarnya proses melakukan pengukuran, yaitu memberikan nilai atau ukuran terhadap variabel yang diteliti menurut indikator-indikator yang dapat diobservasi. Dalam penelitian ini terdapat dua variabel yang diteliti, yaitu faktor fundamental sebagai variabel bebas, yaitu Simpanan Berjangka (X), dan Dana Baitul Maal sebagai variabel terikat $(\mathrm{Y})$.

Dalam penelitian ini operasional variabelnya adalah sebagai berikut :

\begin{tabular}{|c|l|c|}
\hline Variabel & \multicolumn{1}{|c|}{ Indikator } & Skala \\
\hline $\begin{array}{c}\text { Simpanan } \\
\text { Berjangka }\end{array}$ & $\begin{array}{l}\text { Simpanan yang } \\
\text { pengambilannya hanya } \\
\text { dapat dilakukan pada } \\
\text { waktu tertentu sesuai } \\
\text { kesepakatan. }\end{array}$ & $\begin{array}{c}\text { Skala } \\
\text { Ordinal }\end{array}$ \\
\hline X) & $\begin{array}{l}\text { Jumlah dari } \\
\text { penghimpunan dana } \\
\text { Baitul } \\
\text { ziswaf KJKS BMT }\end{array}$ & Skala \\
Maal (Y) & $\begin{array}{l}\text { Umat Sejahtera untuk } \\
\text { ditasarufkan kembali. }\end{array}$ & \\
& \\
\hline
\end{tabular}

Sumber : Data Diolah

\section{Analisis Data dan Uji Hipotesis}

\section{A. Analisi Data}

Analisis data pada pengujian hipotesis dimaksudkan untuk mengetahui ada tidaknya pengaruh simpanan berjangka terhadap dana baitul maal sebagai implementasi Corporate Social Responsibility. Analisis ini dilakukan dengan menggunakan analisis koefisien korelasi dan analisis regresi sederhana.

\section{Analisis Koefisien Korelasi}

Analisis Koefisien Korelasi digunakan untuk mengetahui bagaimana pengaruh simpanan berjangka terhadap dana baitul maal sebagai implementasi Corporate Social Responsibility di KJKS BMT Umat Sejahtera yang dinyatakan dengan persamaan korelasi pearson (product moment) dengan rumus

$$
\begin{aligned}
& r=\frac{n \sum(x y)-\sum x \sum y}{\sqrt{\left[n \sum x^{2}-\left(\sum x\right)^{2}\right]\left[n\left(\sum Y 2\right)-\left(\sum Y\right)^{2}\right.}} \\
& \text { Keterangan : } \\
& \mathrm{r}=\text { korelasi product moment } \\
& \mathrm{x}=\text { simpanan berjangka } \\
& \mathrm{y}=\text { dana baitul maal } \\
& \mathrm{n}=\text { jumlah sampel } \\
& \text { Tabel. Pedoman Untuk Memberikan } \\
& \text { Interpretasi Koefisien Korelasi }
\end{aligned}
$$

\begin{tabular}{|l|l|}
\hline $\begin{array}{l}\text { Interval } \\
\text { Koefisien }\end{array}$ & Tingkat Hubungan \\
\hline $0,00-0,199$ & Sangat Rendah \\
$0,20-0,399$ & Rendah \\
$0,40-0,599$ & Sedang \\
$0,60-0,799$ & Kuat \\
$0,80-1,000$ & Sangat Kuat \\
\hline
\end{tabular}

Sumber : Dr.Sugiyono(2008: 242)

Koefisien determinasi dapat dihitung dengan cara mengkuadratkan koefisien yang ditemukan. Perhitungan koefisien determinasi digunakan untuk menghitung besarnya varian variabel independen terhadap variabel dependen.

\section{Analisis Regresi Sederhana}

Regresi merupakan suatu alat ukur yang juga digunakan untuk mengukur ada atau tidaknya korelasi antar variabelnya. Dalam hal ini maka analisis regresi sederhana digunakan untuk mengukur adanya pengaruh atau hubungan antara simpanan berjangka terhadap dana baitul maal sebagai implementasi Corporate Social Responsibility.

Adapun bentuk umum dari persamaan regresi sederhana adalah sebagai berikut :

$$
\begin{aligned}
& \mathrm{Y}=\mathrm{a}+\mathrm{b}(\mathrm{X}) \\
& \mathrm{a}=\text { Konstanta } \\
& \mathrm{b}=\text { Koefisien Regresi } \\
& \mathrm{X}=\text { Simpanan Berjangka } \\
& \mathrm{Y}=\text { Dana Baitul Maal } \\
& \mathrm{b}=\frac{\mathrm{n}\left(\sum \mathrm{x} \mathrm{y}\right)-\left(\sum \mathrm{x}\right)\left(\sum \mathrm{y}\right)}{\mathrm{n}\left(\sum \mathrm{x}^{2}\right)\left(\sum \mathrm{x}\right)^{2}}
\end{aligned}
$$$$
\mathrm{a}=\frac{\sum \mathrm{y}-\mathrm{b}\left(\sum \mathrm{x}\right)}{\mathrm{n}}
$$

\section{Kesalahan Standar Estimasi}

Untuk mengetahui ketepatan persamaan estimasi dapat digunakan dengan mengukur besar kecilnya kesalahan standar estimasi. Semakin kecil nilai kesalahan standar estimasi maka semakin tinggi ketepatan persamaan estimasi yang dihasilkan untuk menjelaskan nilai variabel yang sesungguhnya. Sebaliknya semakin besar nilai kesalahan estimasi maka semakin rendah ketepatan persamaan estimasi yang dihasilkan untuk menjelaskan nilai variabel dependen yang sesungguhnya. Kesalahan standar estimasi diberi simbol Se yang dapat ditentukan dengan rumus sebagai berikut : 


$$
S e=\sqrt{\frac{\sum \mathrm{Y}^{2}-\mathrm{a} \sum \mathrm{Y}-\mathrm{b} \sum \mathrm{XY}}{n-2}}
$$

a $=$ konstanta

$\mathrm{b}=$ koefisien regresi

$\mathrm{n} \quad$ jarak waktu

$\sum \mathrm{Y}=$ Jumlah variabel dependen

$\sum \mathrm{Y}^{2}=$ Jumlah dari variabel dependen yang dikuwadratkan

\section{B. Uji Hipotesis}

Rancangan pengujian hipotesis ini untuk membuktikan apakah Simpanan Berjangka (X) memiliki hubungan dengan Dana Baitul Maal (Y). Pengujian ini digunakan untuk membuktikan $\mathrm{H}_{\mathrm{o}}$ atau $\mathrm{H}_{\mathrm{a}}$ akan diterima atau tidak maka dilakukan uji hipotesis nol dimana

Ho $: \rho=0$ artinya simpanan berjangka tidak berpengaruh terhadap baitul maal sebagai implementasi Corporate Social Responsibility.

Ha $: \rho \neq 0$, artinya simpanan berjangka berpengaruh terhadap dana baitul maal sebagai Corporate Social Responsibility.

Untuk menguji hipotesis signifikan menurut Sugiyono (2012:184) digunakan uji $t$ dengan formula $t=\sqrt[r]{\frac{(n-2)}{1-r^{2}}}$

Dengan kriteria ujiannya adalah

1) Ho diterima jika $t_{\text {hitung }}<t$ tabel

2) Ha diterima jika $t$ hitung $>t$ tabel

3) $t_{\text {tabel }}$ dicari dalam tabel distribusi $t$ dengan $\mathrm{a}=0,05(5 \%)$ dengan $\mathrm{dk}=\mathrm{n}-2$.

\section{ANALISIS HASIL PENELITIAN}

\section{Kondisi Simpanan Berjangka di KJKS BMT Umat Sejahtera}

Simpanan Berjangka merupakan simpanan dengan jumlah tertentu yang memiliki jangka waktu tertentu dalam penarikannya. Akan tetapi walaupun demikian Simpanan Berjangka cukup banyak diminati para pemilik dana untuk investasi jangka panjang khususnya di KJKS BMT Umat Sejahtera, dikarenakan bagi hasil yang diperoleh dari simpanan berjangka cukuplah besar.

Hal ini dibuktikan dengan kenaikan jumlah Simpanan Berjangka setiap tahunnya di KJKS BMT Umat Sejahtera. Simpanan Berjangka berdasarkan jangka waktu simpanannya ada beberapa macam diantaranya :

a. Simpanan Berjangka 3 Bulan

Merupakan simpanan berjangka yang memiliki jangka waktu selama 3 bulan. simpanan berjangka 3 bulan adalah simpanan berjangka yang memiliki jangka waktu tercepat. Nisbah atau bagi hasil untuk simpanan berjangka 3 bulan di KJKS BMT Umat Sejahtera adalah 26\%: $74 \%$ atau setara dengan $0.4089 \%$ maksudnya adalah dari sejumlah uang yang disimpanan berjangka-kan 3 bulan akan mendapat bagi hasil 26\% untuk pemilik dana dan 74\% untuk BMT sebagai pengelola berdasarkan

b. Simpanan Berjangka 6 Bulan

Simpanan berjangka 6 bulan adalah simpanan berjangka yang memiliki jangka waktu selama 6 bulan. Untuk nisbah simpanan berjangka 6 bulan di KJKS BMT Umat Sejahtera adalah sebesar 32\%: $68 \%$ atau setara $0.5032 \%$ dimana setiap bulan pemilik dana akan menerima bagi hasil dari KJKS BMT Umat Sejahtera dengan prosentase kurang lebih $0.5032 \%$ dari nominal uang yang disimpan. Jumlah bagi hasil setiap bulan bisa naik turun tergantung dari pendapatan KJKS BMT Umat Sejahtera pada bulan tersebut.

c. Simpanan Berjangka 12 bulan

Simpanan berjangka 12 bulan merupakan simpanan berjangka yang memiliki jangka waktu paling lama. Nisbah simpanan berjangka 12 bulan yang diberikan paling besar dibanding simpanan berjangka yang lain, karena jangka waktu yang diberikan pemilik dana lebih lama sehingga pihak KJKS BMT Umat Sejahtera lebih mudah dalam mengelola dana tersebut, yaitu $52 \%$ : $48 \%$ atau setara $0.8177 \%$.

Tabel 3.1Data Produk Simpanan Berjangka 2014 Sumber : RAT XI KJKS BMT Umat Sejahtera

Dari jumlah Simpanan Berjangka tersebut, didominasi oleh simpanan berjangka 12 bulan yaitu sebesar Rp 2.705.750.000 pada tahun 2014 dari tahun sebelumnya yang mencapai Rp 1.912.700.000 atau naik sebesar Rp 793.050.000 setara 41,462\%. Akan tetapi meski jumlah SIMKA 12 bulan mendominasi simpanan berjangka di KJKS BMT Umat Sejahtera, SIMKA 3 bulan mengalami kenaikan yang lebih signifikan dibanding SIMKA 12 bulan maupun simpanan berjangka 6 bulan.

\begin{tabular}{|l|l|l|l|l|}
\hline $\begin{array}{l}\text { Produk } \\
\text { SIMKA }\end{array}$ & Desember 2013 & Desember 2014 & Perubahan & $\%$ \\
\hline SIMKA 3 bln & $\begin{array}{l}\mathrm{Rp} \\
493.500 .000\end{array}$ & $\begin{array}{l}\mathrm{Rp} \\
1.485500 .000\end{array}$ & $\begin{array}{l}\mathrm{Rp} \\
992.000 .000\end{array}$ & $\begin{array}{l}201.01 \\
\%\end{array}$ \\
\hline SIMKA 6 bln & $\begin{array}{l}\mathrm{Rp} \\
246.500 .000\end{array}$ & $\begin{array}{l}\mathrm{Rp} \\
280.000 .000\end{array}$ & $\begin{array}{l}\mathrm{Rp} \\
33.500 .000\end{array}$ & $\begin{array}{l}13.59 \\
\%\end{array}$ \\
\hline $\begin{array}{l}\text { SIMKA 12 } \\
\text { bln }\end{array}$ & $\begin{array}{l}\mathrm{Rp} \\
1.912 .700 .000\end{array}$ & $\begin{array}{l}\text { Rp } 2.705 .750 .000 \\
\text { Rp }\end{array}$ & $\begin{array}{l}\text { R93.050.000 } \\
\%\end{array}$ \\
\hline
\end{tabular}

Simka 3 bulan yang pada tahun 2013 jumlahnya pada angka Rp 493.500.000 pada tahun 2014 mengalami kenaikan sebesar $201,01 \%$ atau naik Rp 992.000.000 sehingga pada tahun 2014 mencapai Rp 1.485.500.000. Sedangkan untuk simpanan berjangka 6 bulan hanya mengalamai kenaikan 
EKSISBANK Vol. 3 No. 1 Juni 2019

sebesar Rp 33.500 .000 setara $13,59 \%$ dari sebelumnya $\mathrm{Rp} \quad 246.500 .000$ menjadi $\mathrm{Rp}$ 280.000.000 pada tahun 2014 .

\section{Baitul Maal Umat Sejahtera sebagai Implementasi Corporate Social Responsibility}

Dilihat dari ruang lingkup kegiatan yang bertujuan untuk kegiatan sosial, eksistensi Corporate Social Responsibility di KJKS BMT Umat Sejahtera dituangkan secara jelas dalam Baitul Maal Umat Sejahtera. Selain menghimpun dana dari para donatur, lembaga ini juga menghimpun dana Corporate Social Responsibility dari karyawan dan nasabahnya serta dari zakat lembaga yang diambil dari pendapatan bersih Baitul Tamwil Umat Sejahtera. Jadi KJKS BMT Umat Sejahtera benar menjalankan Corporate Social Responsibility sebagaimana seperti pada pegertian Corporate Social Responsibility yang merupakan tanggungjawab sosial perusahaan adalah kewajiban organisasi untuk berbuat dengan cara tertentu yang ditujukan untuk melayani kepentingannya sendiri maupun kepentingan stakeholder. Dari pemaparan tersebut dapat diketahui bahwa Baitul Maal Umat Sejahtera adalah sebagai penggerak atau fungsi dari implementasi dana Corporate Social Responsibility yang dikelola dan dihimpun.

Pelaksanaan Corporate Social Responsibility diwujudkan dalam program - program unggulan diantaranya sebagai berikut :

1) Beastu di Dhuafa Berprestasi

Beastudi dhuafa berprestasi merupakan kegiatan sosial yang ditujukan kepeda siswa siswi berprestasi SMP \& SMA di Kabupaten Kebumen yang memiliki prestasi lebih tetapi kurang mampu dalam hal keuangan. Sebanyak 21 siswa - siswi SMA \& SMK serta 20 siswa siswi SMP mendapatkan beastudi berupa bebas SPP dan juga bimbingan belajar untuk mata pelajaran matematika dan bahasa inggris. Selain itu peserta beastudi juga mendapatkan motivasi keagamaan yang diharapkan dari adanya kegiatan ini, Baitul Maal KJKS BMT Umat Sejahtera mampu membantu mencetak generasi yang berilmu dan berakhlak mulia.

Berikut Data Sekolah Siswa Penerima Beastudi Baitul Maal Umat Sejahtera tahun 2014

Tabel 3.2 Data Sekolah Penerima Beastudi

\begin{tabular}{|c|l|l|l|l|}
\hline No & Nama Sekolah & Semester 1 & Semester 2 & Jumlah \\
\hline & SMP PGRI 1 & $\mathrm{Rp}$ & & $\mathrm{Rp}$ \\
1 & Buluspesantren & 600.000 & & 600.000 \\
\hline & Mts Ay & & & \\
& Yusufiyah & $\mathrm{Rp}$ & & $\mathrm{Rp}$ \\
2 & Sangubanyu & 600.000 & & 600.000 \\
\hline & Mts Maárif & $\mathrm{Rp}$ & & $\mathrm{Rp}$ \\
3 & Karangsambung & 600.000 & & 600.000 \\
\hline & SMP N 1 & $\mathrm{Rp}$ & & $\mathrm{Rp}$ \\
4 & Karangsambung & 600.000 & & 600.000 \\
\hline
\end{tabular}

\begin{tabular}{|c|c|c|c|c|}
\hline 5 & $\begin{array}{l}\text { Mts N Triwarno } \\
\text { Kutowinangun }\end{array}$ & $\begin{array}{l}\mathrm{Rp} \\
600.000\end{array}$ & & $\begin{array}{l}\mathrm{Rp} \\
600.000\end{array}$ \\
\hline 6 & $\begin{array}{l}\text { Mts Maárif } \\
\text { Lumbu }\end{array}$ & $\begin{array}{l}\mathrm{Rp} \\
600.000\end{array}$ & & $\begin{array}{l}\mathrm{Rp} \\
600.000\end{array}$ \\
\hline 7 & $\begin{array}{l}\text { Mts An Nawawi } \\
\text { 03 Kebumen }\end{array}$ & $\begin{array}{l}\mathrm{Rp} \\
600.000\end{array}$ & & $\begin{array}{l}\mathrm{Rp} \\
600.000\end{array}$ \\
\hline 8 & $\begin{array}{l}\text { Mts Salafiyah } \\
\text { Wonoyoso } \\
\text { Kebumen }\end{array}$ & $\begin{array}{l}\mathrm{Rp} \\
600.000\end{array}$ & & $\begin{array}{l}\mathrm{Rp} \\
600.000\end{array}$ \\
\hline 9 & $\begin{array}{l}\text { Mts Khaudul } \\
\text { Úlum }\end{array}$ & $\begin{array}{l}\mathrm{Rp} \\
600.000\end{array}$ & & $\begin{array}{l}\mathrm{Rp} \\
600.000\end{array}$ \\
\hline 10 & $\begin{array}{l}\text { SMP Maárif } 2 \\
\text { Alian }\end{array}$ & $\begin{array}{l}\mathrm{Rp} \\
600.000\end{array}$ & & $\begin{array}{l}\mathrm{Rp} \\
600.000\end{array}$ \\
\hline 11 & $\begin{array}{l}\text { SMP N } 1 \\
\text { Kebumen }\end{array}$ & & $\begin{array}{l}\mathrm{Rp} \\
480.000\end{array}$ & $\begin{array}{l}\mathrm{Rp} \\
480.000\end{array}$ \\
\hline 12 & $\begin{array}{l}\text { SMP N } 6 \\
\text { Kebumen }\end{array}$ & $\begin{array}{l}\mathrm{Rp} \\
200.000\end{array}$ & $\begin{array}{l}\mathrm{Rp} \\
100.000\end{array}$ & $\begin{array}{l}\mathrm{Rp} \\
300.000\end{array}$ \\
\hline 13 & $\begin{array}{l}\text { SMP N } 7 \\
\text { Kebumen }\end{array}$ & $\begin{array}{l}\mathrm{Rp} \\
500.000\end{array}$ & & $\begin{array}{l}\mathrm{Rp} \\
500.000\end{array}$ \\
\hline 14 & $\begin{array}{l}\text { SMK N } 1 \\
\text { Kebumen }\end{array}$ & $\begin{array}{l}\mathrm{Rp} \\
4.520 .000\end{array}$ & $\begin{array}{l}\mathrm{Rp} \\
7.100 .000\end{array}$ & $\begin{array}{l}\mathrm{Rp} \\
11.620 .000\end{array}$ \\
\hline 15 & $\begin{array}{l}\text { SMK N } 2 \\
\text { Kebumen } \\
\end{array}$ & $\begin{array}{l}\mathrm{Rp} \\
2.100 .000\end{array}$ & $\begin{array}{l}\mathrm{Rp} \\
900.000\end{array}$ & $\begin{array}{l}\mathrm{Rp} \\
3.000 .000\end{array}$ \\
\hline 16 & $\begin{array}{l}\text { MA N } 1 \\
\text { Kebumen }\end{array}$ & $\begin{array}{l}\mathrm{Rp} \\
500.000\end{array}$ & $\begin{array}{l}\mathrm{Rp} \\
510.000\end{array}$ & $\begin{array}{l}\mathrm{Rp} \\
1.010 .000\end{array}$ \\
\hline 17 & $\begin{array}{l}\text { MA N } 2 \\
\text { Kebumen }\end{array}$ & & $\begin{array}{l}\mathrm{Rp} \\
2.620 .000\end{array}$ & $\begin{array}{l}\mathrm{Rp} \\
2.620 .000\end{array}$ \\
\hline 18 & $\begin{array}{l}\text { SMA N } 1 \\
\text { Kutowinangun } \\
\end{array}$ & $\begin{array}{l}\mathrm{Rp} \\
1.835 .000 \\
\end{array}$ & $\begin{array}{l}\mathrm{Rp} \\
860.000\end{array}$ & $\begin{array}{l}\mathrm{Rp} \\
2.695 .000\end{array}$ \\
\hline 19 & $\begin{array}{l}\text { MA N } 1 \\
\text { Kutowinangun }\end{array}$ & & $\begin{array}{l}\mathrm{Rp} \\
1.000 .000\end{array}$ & $\begin{array}{l}\mathrm{Rp} \\
1.000 .000\end{array}$ \\
\hline 20 & $\begin{array}{l}\text { SMA N } 1 \\
\text { Waluyo }\end{array}$ & & $\begin{array}{l}\mathrm{Rp} \\
1.000 .000 \\
\end{array}$ & $\begin{array}{l}\mathrm{Rp} \\
1.000 .000 \\
\end{array}$ \\
\hline 21 & $\begin{array}{l}\text { SMA N } 1 \\
\text { Kebumen }\end{array}$ & & $\begin{array}{l}\mathrm{Rp} \\
1.300 .000\end{array}$ & $\begin{array}{l}\mathrm{Rp} \\
1.300 .000\end{array}$ \\
\hline & Jumlah & $\begin{array}{l}\text { Rp } \\
15.655 .000\end{array}$ & Rp15.870.000 & $\begin{array}{l}\text { Rp } \\
31.525 .000\end{array}$ \\
\hline
\end{tabular}

Sumber : RAT KJKS BMT Umat Sejahtera 2014

Dari data di atas dapat diketahui bahwa penerima beasiswa terbesar adalah dari tingkat SMA dan SMK Sederajat, yaitu pada SMK N 1 Kebumen Rp 11.620.000 sedangkan untuk pembayaran SPP siswa SMP rata -rata jumlahnya sama sekitar Rp 600.000 walaupun pada SMP N 6 Kebumen hanya mencapai Rp 300.000 untuk 2 semester.

2) Sembako Berkah

Sembako berkah merupakan kegiatan yang ditujukan kepada para fakir, miskin dan dhuafa di daerah sekitar kantor KJKS BMT Umat Sejahtera baik pusat maupun cabang. Kegiatan ini sebagai wujud BMT Perduli kepada mereka yang dirasa kurang mampu, kegiatan ini biasa dilaksanakan menjelang lebaran Idul Fitri dan pada tahun 2014 Baitul Maal Umat Sejahtera telah mentasarufkan sejumlah 374 bingkisan sembako senilai Rp 15.300.000 pada 38 desa di 6 kecamatan (Alian, Kebumen, Poncowarno, Buluspesantren, Karangsambung dan Pejagoan).

3) Program Peduli Guru Ngaji dan Ustadz

Program ini dikhususkan untuk para guru ngaji (ustadz dan ustadzah) yang peduli pada anak - anak di daerah lingkungannya tanpa mengharapkan imbalan. Sejumlah 75 orang guru ngaji telah mendapatkan 
pembinaan dan santunan dari Baitul Maal KJKS BMT Umat Sejahtera pada tahun 2014 dengan dana sejumlah Rp 5.500.000.

4) Pemberdayaan Ekonomi Umat (KUM 3 \& BMT Preneur)

Merupakan program pemberian kredit pinjaman tanpa bunga dan pembinaan usaha bagi mereka masyarakat ekonomi yang kurang mampu tetapi ingin membuka usaha. Selain pemberian pembiayaan dengan akad Qordul Hasan, masyarakat penerima program ini juga mendapatkan pembinaan berupa motivasi, pembukuan menejemen, serta wirausaha pada setiap bulannya. Terdapat 4 kelompok program KUM 3 pada tahun 2014 yaitu Kum 3 Surotrunan, Kum 3 Ambalkumolo, Kum 3 Kalijaya dan Kum 3 Panjer. Masing - masing kelompok Kum 3 yang beranggotakan 5 orang diberikan modal awal sebesar Rp 5.000.000 untuk mengembangkan usahanya dan mengembalikan modal tersebut dengan mengangsur tanpa memberikan bagi hasil kepada KJKS BMT Umat Sejahtera.

Hampir sama dengan KUM 3, BMT Preneur juga memberikan modal usaha dengan akad Qordul Hasan, akan tetapi BMT Preneur bukan berbentuk kelompok tetapi individu dimana setiap anggota akan diberikan modal dengan akad Qordul Hasan dan mendapatkan Hibah peralatan usahanya dari BMT senilai Rp 1.000.000. Pada tahun 2014 ada 7 anggota penerima BMT Preneur dengan beragam jumlah modal usaha hingga total mencapai Rp 25.915.000.

5) Program Tanggap Bencana

Beberapa bencana yang terjadi di Indonesia, khususnya di daerah Kebumen pada tahun 2014, membuat Baitul Maal yang bekerjasama dengan Perhimpunan BMT Indonesia dalam hal ini PBMTI Kabupaten Kebumen saling bahu membahu untuk sedikit meringankan saudara - saudara kita yang terkena musibah, seperti Bencana Gunung Sinabung, Banjir di Kecamatan Krakal, Peduli Bencana Indonesia dan bahkan Peduli Palestina. Dengan bantuan donasi dari para donatur, Baitul Maal Umat Sejahtera mentasarufkan dana sebesar Rp 17.498.000 untuk program tanggap bencana pada tahun 2014.

6) Gerakan Wakaf Qurán

Merupakan program pembagian AlQurán gratis kepada anggota seperti kelompok anggota KUM 3, pengelola KJKS BMT Umat Sejahtera, anggota BMT Preneur, Donatur, Prasarana Masjid dsb.

7) BBM (Bersih - Bersih Masjid / Mushola)
BBM atau Bersih - Bersih Masjid adalah kegiatan yang dilakukan Baitul Maal dalam rangka perduli terhadap kebersihan tempat ibadah umat muslim. Kegiatan ini mencangkup pemberian alat kebersihan masjid, pembersihan karpet masjid dengan vacuum dan pemberian bisaroh kepada petugas kebersihan masjid. Program ini berjalan untuk masjid dan mushola di daerah kantor KJKS BMT Umat Sejahtera.

8) THK (Tebar Hewan Kurban)

Kegiatan yang dilakukan pada lebaran Idul adha ini merupakan kegiatan rutin tahunan di KJKS BMT Umat Sejahtera. BMT Umat Sejahtera selaku panitia menyalurkan kepada daerah - daerah yang masih minim daging kurban agar memeperluas sasaran dan memperlebar syiar Islam melalui realisasi ibadah kurban. Harapan lain agar pada tahun mendatang masyarakat yang mampu menjadi tergugah untuk berupaya melaksanakan kurban sebagai wujud iman dan taqwa kepada Alloh SWT. Pada tahun 2014 sebanyak 79 ekor kambing berhasil dikumpulkan pihak Baitul Maal Umat Sejahtera untuk kemudian disalurkan kepada masyarakat. Jumlah yang sangat besar itu berasal dari dana donatur, dana operasional BMT, dana kurban BMT dan Baitul Maal Umat Sejahtera.

9) Program Lebaran Ceria Anak Yatim

Program yang dilaksanakan pada bulan Ramadhan ini dikhususkan untuk mereka anak yatim atau piatu. Baitul Maal Umat Sejahtera yang bekerjasama dengan Toserba Jadi Baru ini pada tahun 2014 berhasil membawa 106 anak yatim untuk berbelanja kebutuhan lebaran di toserba Jadi Baru dengan voucher sebesar $\mathrm{Rp}$ 150.000/anak. Berdasarkan berbagai kegiatan di atas berikut merupakan laporan peroleha dana Baitul Maal secara singkat dan penyalurannya pada tahun 2014 :

Tabel 3.3 Data Penerimaan dan Penyaluran Ziswaf secara total

\begin{tabular}{|c|c|c|}
\hline & & TOTAL \\
\hline \multicolumn{2}{|c|}{ PENERIMAAN DANA ZAKAT } & $\begin{array}{l}\mathrm{Rp} \\
82,269,682\end{array}$ \\
\hline \multicolumn{3}{|c|}{ PENYALURAN DANA ZAKAT } \\
\hline 1) & FAKIR MISKIN & $\begin{array}{l}\mathrm{Rp} \\
67,449,700\end{array}$ \\
\hline 2) & SABILILLAH & $\begin{array}{l}\mathrm{Rp} \\
8,848,000\end{array}$ \\
\hline 3) & AMIL & $\mathrm{Rp} 400,00$ \\
\hline 4) & GHORIMIN & $\begin{array}{l}\mathrm{Rp} \\
5,266,900\end{array}$ \\
\hline 5) & RIQOB & \\
\hline
\end{tabular}


EKSISBANK Vol. 3 No. 1 Juni 2019

\begin{tabular}{|l|l|l|}
\hline 6$)$ & IBNU SABIL & \\
\hline 7$)$ & MUALAF & \\
\hline JUMLAH PENYALURAN DANA ZAKAT & $\mathrm{Rp}$ \\
$81,964,600$
\end{tabular}

Tabel di atas menunjukan perputaran dana Baitul Maal untuk berbagai kegiatan Coorporate Social Responsibility di KJKS BMT Umat Sejahtera, terlihat jelas penerimaan dana zakat secara total sebesar Rp 82.269.682 dan penyalurannya terbesar pada fakir miskin $\mathrm{Rp}$ 14.116.300. Sedangkan untuk penyaluran sabililah dari dana zakat secara total yaitu sebesar Rp 40.173.700.

Penerimaan dana infaq terdapat pada secara total yaitu sebesar Rp 235.898.300 Sedangkan Penerimaan dana wakaf selama tahun 2014 mencapai $\mathrm{Rp} 4.560 .000$ dan belum disalurkan karena pembangunan Masjid Baitul Maal dibangun pada tahun 2015.

Dari tabel di atas apabila diperinci mendapatkan hasil sebagai berikut :

a. Perolehan

\begin{tabular}{|c|c|}
\hline Zakat & 56.502 .258 \\
\hline Infaq dan Shodaqoh & : Rp 256.862.180 \\
\hline Wakaf Uang & : Rp 18.314 .378 \\
\hline Wakaf Mushola & : Rp 155.860.500 \\
\hline Jumlah & : Rp 487.539.316 \\
\hline Penyaluran & \\
\hline Zakat & : Rp 61.179.150 \\
\hline Infaq & : Rp 268.127.250 \\
\hline Wakaf Mushola & : Rp 145.521.200 \\
\hline Jumlah & : Rp 474.827.600 \\
\hline Sisa Saldo 2014 & $: \operatorname{Rp} 12.711 .716$ \\
\hline
\end{tabular}

Dari berbagai keterangan kegiatan di atas Corporate Social Responsibility KJKS BMT
Umat Sejahtera dalam hal ini Baitul Maal memberikan manfaat yang sangat besar dalam menyejahterakan masyarakat dan melestarikan lingkungan sekitarnya, serta bentuk investasi bagi perusahaan pelakunya. Investasi bagi perusahaan dapat berupa jaminan keberlanjutan operasi perusahaan dan pembentukan citra positif perusahaan. Meskipun kegiatan Coorporate Social Responsibility membutuhkan dana yang cukup besar akantetapi berbagai upaya telah dilakukan untuk mendapatkan sumber dana tanpa memberatkan perusahaan. Dan berbagai manfaat telah diperoleh KJKS BMT Umat Sejahtera sehingga dapat menjadi kepercayaan masyarakat sekitar dengan menjadi koperasi terbaik dan mendapat berbagai penghargaan dari penerapan Corporate Social Responsibility atas dasar kesukarelaan, sehingga timbul hubungan timbal balik antara pihak perusahaan dengan masyarakat sekitar. Masyarakat akan secara sukarela membela keberlanjutan perusahaan tersebut dan memberikan persepsi yang baik pada perusahaan. Dengan begitu citra positif perusahaan akan terbentuk dengan sendirinya.

3. Pengaruh Simpanan Berjangka terhadap Dana Baitul Maal sebagai Implementasi Corporate Social Responsibility

Keberhasilan Baitul Maal sebagai Coorporate Social Responsibility dalam membangun citra baik masyarakat terhadap KJKS BMT Umat Sejahtera tidaklah mudah karena dibutuhkan dana yang cukup besar untuk dapat mensukseskan berbagai kegiatannya. Berbagai pihak berpartisipasi dalam kegiatan pengumpulan dana dan dalam kegiatan kegiatan Corporate Social Responsibility tersebut. Simpanan Berjangka yang merupakan salah satu produk KJKS BMT Umat Sejahtera juga ikut berpartisipasi dalam pengumpulan dana Baitul Maal untuk kegiatan Corporate Sosial Responsibility di KJKS BMT Umat Sejahtera. Simpanan Berjangka yang mendapatkan bagi hasil setiap bulannya memberikan konstribusi terhadap Baitul Maal dari ziswaf bagi hasil simpanan berjangka sebesar 2.5\%. Meski jumlah ini tidak terlalu signifikan, tetapi jika diakumulasikan dari total jumlah simpanan berjangka di KJKS BMT Umat Sejahtera selama tahun 2014 maka akan mendapatkan jumlah yang cukup banyak. Kemudian dana ziswaf bagi hasil simpanan berjangka tersebut dikelola oleh pihak Baitul Maal sebagai dana Corporate Sosial Responsibility di KJKS BMT Umat Sejahtera.

Pada pembahasan sebelumnya telah dijelaskan perolehan dan pentasarufan dana Baitul Maal sebagai Corporate Social Responsibility, di bawah ini akan dijelaskan 


\section{EKSISBANK Vol. 3 No. 1 Juni 2019}

akumulasi jumlah simpanan berjangka setiap bulan, baik simpanan berjanngka 3 bulan, simpanan berjangka 6 bulan maupun simpanan berjangka 12 bulan selama tahun 2014 dari bulan Januai sampai Desember :

Tabel 3.4 Simpanan Berjangka BMT Umat Sejahtera Per-Bulan 2014 (Dalam jutaan)

\begin{tabular}{|c|c|c|c|c|c|}
\hline NO. & BULAN & $\begin{array}{l}\text { SIMKA } 3 \\
\text { BULAN }\end{array}$ & $\begin{array}{l}\text { SIMKA } 6 \\
\text { BULAN }\end{array}$ & $\begin{array}{l}\text { SIMKA } 12 \\
\text { BULAN }\end{array}$ & JUMLAH \\
\hline 1 & JANUARI & Rp405,0 & Rp242,5 & Rp1.985,7 & Rp2.633,2 \\
\hline 2 & FEBRUARI & Rp302,5 & Rp261,5 & Rp2.011,5 & $\mathrm{Rp} 2.575,5$ \\
\hline 3 & MARET & $\mathrm{Rp} 332,5$ & Rp290,0 & Rp1.974,0 & Rp2.596,5 \\
\hline 4 & APRIL & $\mathrm{Rp} 251,0$ & Rp239,0 & Rp1.964,0 & $\mathrm{Rp} 2.454,0$ \\
\hline 5 & MEI & $\mathrm{Rp} 244,0$ & Rp221,0 & Rp1.855,5 & Rp2.320,5 \\
\hline 6 & JUNI & Rp202,5 & Rp113,0 & Rp1.867,0 & Rp2.182,5 \\
\hline 7 & JULI & Rp175,0 & Rp101,0 & Rp1.917,5 & Rp2.193,5 \\
\hline 8 & AGUSTUS & $\mathrm{Rp} 230,0$ & Rp131,0 & $\mathrm{Rp} 2.228,5$ & Rp2.589,5 \\
\hline 9 & SEPTEMBER & Rp227,0 & Rp174,5 & $\mathrm{Rp} 2.314,8$ & Rp2.716,3 \\
\hline 10 & OKTOBER & Rp836,5 & Rp188,5 & $\mathrm{Rp} 2.428,8$ & Rp3.453,8 \\
\hline 11 & NOVEMBER & Rp1.201,5 & $\mathrm{Rp} 243,5$ & Rp2.484,8 & Rp3.929,8 \\
\hline 12 & DESEMBER & Rp1.485,5 & $\mathrm{Rp} 280,0$ & $\mathrm{Rp} 2.705,8$ & $\mathrm{Rp} 4.471,3$ \\
\hline \multicolumn{2}{|c|}{ JUMLAH } & Rp5.893,0 & Rp2.485,5 & Rp25.737,7 & Rp34.116,2 \\
\hline
\end{tabular}

Tabel di atas menunjukan perputaran dana Baitul Maal untuk berbagai kegiatan Coorporate Social Responsibility di KJKS BMT Umat Sejahtera, terlihat jelas penerimaan dana zakat terbesar terdapat pada bulan Juli sebesar Rp 24.786.071 dan penyalurannya terbesar pada fakir miskin Rp 32.140.000. Sedangkan untuk penyaluran sabililah dari dana zakat terbesar pada bulan juli yaitu sebesar Rp 4.462.000. Sedangkan pentasarufan untuk ghorimin dari dana zakat hanya ada pada bulan Oktober yaitu Rp 5.266.900.

Penerimaan dana infaq terdapat pada bulan Oktober yaitu sebesar Rp 140.107.409 begitupun penyalurannya juga terdapat pada bulan Oktober dikarenakan terdapat kegiatan THK (Tebar Hewan Kurban) yang menghabiskan dana sebesar Rp 134.400.000. Sedangkan Penerimaan dana wakaf selama tahun 2014 mencapai Rp 4.560.000 dan belum disalurkan karena pembangunan Masjid Baitul Maal dibangun pada tahun 2015.

Dari tabel di atas apabila diperinci mendapatkan hasil sebagai berikut :

c. Perolehan

Zakat

: Rp 56.502 .258

$\begin{array}{ll}\text { Infaq dan Shodaqoh } & : \operatorname{Rp} 256.862 .180 \\ \text { Wakaf Uang } & : \operatorname{Rp} 18.314 .378 \\ \text { Wakaf Mushola } & : \operatorname{Rp} 155.860 .500 \\ \text { Jumlah } & : \operatorname{Rp} 487.539 .316 \\ \text { Penyaluran } & \\ \text { Zakat } & : \operatorname{Rp} 61.179 .150 \\ \text { Infaq } & : \operatorname{Rp} 268.127 .250 \\ \text { Wakaf Mushola } & : \operatorname{Rp} 145.521 .200 \\ \text { Jumlah } & : \operatorname{Rp} 474.827 .600 \\ \text { Sisa Saldo 2014 } & : \operatorname{Rp} 12.711 .716\end{array}$

Dari berbagai keterangan kegiatan di atas Corporate Social Responsibility KJKS BMT Umat Sejahtera dalam hal ini Baitul Maal memberikan manfaat yang sangat besar dalam menyejahterakan masyarakat dan melestarikan lingkungan sekitarnya, serta bentuk investasi bagi perusahaan pelakunya. Investasi bagi perusahaan dapat berupa jaminan keberlanjutan operasi perusahaan dan pembentukan citra positif perusahaan. Meskipun kegiatan Coorporate Social Responsibility membutuhkan dana yang cukup besar akantetapi berbagai upaya telah dilakukan untuk mendapatkan sumber dana tanpa memberatkan perusahaan. Dan berbagai manfaat telah diperoleh KJKS BMT Umat Sejahtera sehingga dapat menjadi kepercayaan masyarakat sekitar dengan menjadi koperasi terbaik dan mendapat berbagai penghargaan dari penerapan Corporate Social Responsibility atas dasar kesukarelaan, sehingga timbul hubungan timbal balik antara pihak perusahaan dengan masyarakat sekitar. Masyarakat akan secara sukarela membela keberlanjutan perusahaan tersebut dan memberikan persepsi yang baik pada perusahaan. Dengan begitu citra positif perusahaan akan terbentuk dengan sendirinya.

4. Pengaruh Simpanan Berjangka terhadap Dana Baitul Maal sebagai Implementasi Corporate Social Responsibility

Keberhasilan Baitul Maal sebagai Coorporate Social Responsibility dalam membangun citra baik masyarakat terhadap KJKS BMT Umat Sejahtera tidaklah mudah karena dibutuhkan dana yang cukup besar untuk dapat mensukseskan berbagai kegiatannya. Berbagai pihak berpartisipasi dalam kegiatan pengumpulan dana dan dalam kegiatan kegiatan Corporate Social Responsibility tersebut. Simpanan Berjangka yang merupakan salah satu produk KJKS BMT Umat Sejahtera juga ikut berpartisipasi dalam pengumpulan dana Baitul Maal untuk kegiatan Corporate Sosial Responsibility di KJKS BMT Umat Sejahtera. Simpanan Berjangka yang mendapatkan bagi hasil setiap bulannya memberikan konstribusi 


\section{EKSISBANK Vol. 3 No. 1 Juni 2019}

terhadap Baitul Maal dari ziswaf bagi hasil simpanan berjangka sebesar $2.5 \%$.

Meski jumlah ini tidak terlalu signifikan, tetapi jika diakumulasikan dari total jumlah simpanan berjangka di KJKS BMT Umat Sejahtera selama tahun 2014 maka akan mendapatkan jumlah yang cukup banyak. Kemudian dana ziswaf bagi hasil simpanan berjangka tersebut dikelola oleh pihak Baitul Maal sebagai dana Corporate Sosial Responsibility di KJKS BMT Umat Sejahtera.

Pada pembahasan sebelumnya telah dijelaskan perolehan dan pentasarufan dana Baitul Maal sebagai Corporate Social Responsibility, di bawah ini akan dijelaskan akumulasi jumlah simpanan berjangka setiap bulan, baik simpanan berjanngka 3 bulan, simpanan berjangka 6 bulan maupun simpanan berjangka 12 bulan selama tahun 2014 dari bulan Januai sampai Desember :

Tabel 3.4. Simpanan Berjangka KJKS BMT Umat Sejahtera Per-Bulan

Terlihat dengan jelas bahwa simpanan berjangka di KJKS BMT Umat Sejahtera didominasi oleh simpanan berjangka 12 bulan. Perolehan simpanan berjangka terbesar ada pada bulan Desember, dikarenakan pada bulan diakhir tahun ini terdapat banyak promo spesial untuk simpanan berjangka sehingga perolehannya mencapai $\mathrm{Rp}$ 4.471.250.000.

Dari berbagai data di atas adalah data yang akan dihitung dan digunakan untuk mengetahui suatu variabel mempengaruhi variabel lainnya. Analisis statistik data hasil penelitian ini dilakukan untuk melihat besarnya pengaruh simpanan berjangka terhadap dana Baitul Maal sebagai implementasi Corporate Social Responsibility secara deskriptif dan analisis statistik data yang digunakan adalah analisis regresi sederhana. Adapun data yang digunakan dalam menghitung pengaruh dana simpanan berjangka terhadap dana Baitul Maal sebagai Coorporate Social Responsibility adalah sebagai berikut.

Tabel 3.5. Simpanan Berjangka dan Dana Baitul Maal BMT Umat Sejantera 2014

\begin{tabular}{|l|l|l|l|}
\hline No. & SIMKA (X) & $\begin{array}{l}\text { Dana } \\
\text { Baitul } \\
\text { Maal (Y) }\end{array}$ & XY \\
\hline 1. & Rp2.633.200.000 & 11.388 .259 & $2,99875636+10^{16}$ \\
\hline 2. & Rp2.575.500.000 & 18.847 .039 & $4,854054894+10^{16}$ \\
\hline 3. & Rp2.596.500.000 & 15.200 .884 & $3,946909531+10^{16}$ \\
\hline
\end{tabular}

\begin{tabular}{|l|l|l|l|}
\hline 4. & $R p 2.454 .000 .000$ & 22.728 .099 & $5,577475495+10^{16}$ \\
\hline 5. & $R p 2.320 .500 .000$ & 12.239 .456 & $2,840165765+10^{16}$ \\
\hline 6. & Rp2.182.500.000 & 12.396 .985 & $2,705641976+10^{16}$ \\
\hline 7. & Rp2.193.500.000 & 37.334 .474 & $8,189316872+10^{16}$ \\
\hline 8. & Rp2.589.500.000 & 15.655 .096 & $4,053887109+10^{16}$ \\
\hline 9. & Rp2.716.250.000 & 10.935 .776 & $2,970430156+10^{16}$ \\
\hline 10. & Rp3.453.750.000 & 142.195 .292 & $4,911069897+10^{17}$ \\
\hline 11. & Rp3.929.750.000 & 11.696 .763 & $4,59653544+10^{16}$ \\
\hline 12. & Rp4.471.250.000 & 24.278 .106 & $1,085534815+10^{17}$ \\
\hline Total & Rp34.116.200.000 & $\mathbf{3 3 4 . 8 9 6 . 2 2 9}$ & $\mathbf{1 , 1 4 2 5 3 8 6 7 3 + 1 0 1 9}$ \\
\hline
\end{tabular}

\begin{tabular}{|c|c|}
\hline $\mathbf{X}^{2}$ & $\mathbf{Y}^{2}$ \\
\hline $6,93374224+10^{18}$ & $1,296924431+10^{14}$ \\
\hline $6,63320025+10^{18}$ & $3,552108791+10^{14}$ \\
\hline $6,74181225+10^{18}$ & $2,310668744+10^{14}$ \\
\hline $6,022116+10^{18}$ & $5,165664842+10^{14}$ \\
\hline $5,38472025+10^{18}$ & $1,498042832+10^{14}$ \\
\hline $4,76330625+10^{18}$ & $1,536852371+10^{14}$ \\
\hline $4,81144225+10^{18}$ & $1,393862949+10^{15}$ \\
\hline $6,70551025+10^{18}$ & $2,450820308+10^{14}$ \\
\hline $7,378014062+10^{18}$ & $1,195911967+10^{14}$ \\
\hline $1,192838906+10^{19}$ & $2,021950107+10^{16}$ \\
\hline $1,1544293506+10^{19}$ & $1,368142647+10^{14}$ \\
\hline $1,1999207656+10^{19}$ & $5,894264309+10^{14}$ \\
\hline $1,163915102+10^{21}$ & $1,121554842+10^{17}$ \\
\hline
\end{tabular}

Simpanan berjangka merupakan variabel $\mathrm{X}$ dan dana Baitul Maal merupakan variabel Y sehingga untuk mengetahui perhitungan variabel bagian 1 maka masing - masing dari variabel dikuwadratkan untuk kemudian digunakan untuk menghitung koefisien korelasi di bawah ini

a. Koefisien Korelasi

$$
=\frac{n \sum(x y)-\sum x \sum y}{\sqrt{\left[1 2 ( 1 , 1 6 3 9 1 5 1 0 2 + 1 0 ^ { 2 1 } - ( 3 4 , 1 1 6 , 2 0 0 . 0 0 0 ) ^ { 2 } ] \left[12\left(1,121554842+10^{17}\right)-(334,896.229)^{2}\right.\right.}}
$$


EKSISBANK Vol. 3 No. 1 Juni 2019

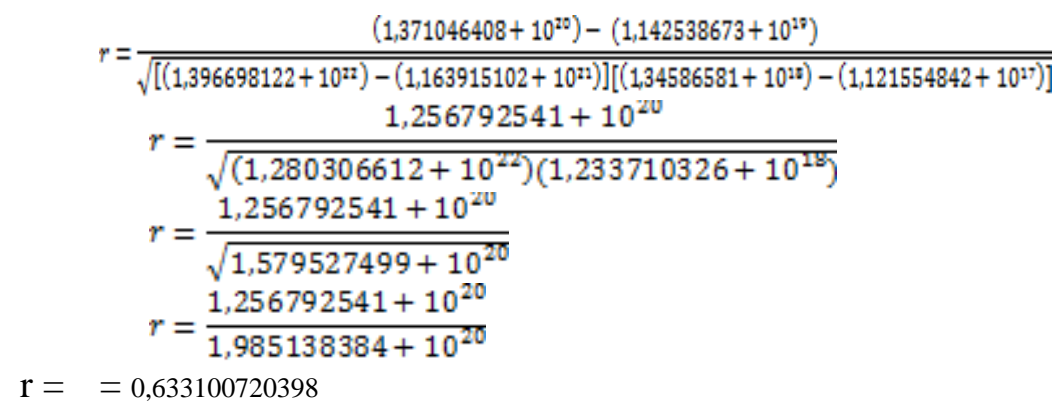

Tabel. Pedoman Untuk Memberikan Interpretasi

Koefisien Korelasi

\begin{tabular}{|l|l|}
\hline $\begin{array}{l}\text { Interval } \\
\text { Koefisien }\end{array}$ & Tingkat Hubungan \\
\hline $0,00-0,199$ & Sangat Rendah \\
$0,20-0,399$ & Rendah \\
$0,40-0,599$ & Sedang \\
$0,60-0,799$ & Kuat \\
$0,80-1,000$ & Sangat Kuat \\
\hline
\end{tabular}

Sumber : Sugiyono(2008: 242)

Berdasarkan tabel pedoman di atas, maka koefisien korelasi yang ditemukan sebesar 0,633 termasuk dalam katagori kuat. Jadi terdapat hubungan yang kuat antara simpanan berjangka dengan dana Baitul Maal sebagai Coorporate Sosial Responsibility di KJKS BMT Umat Sejahtera.

b. Koefisien Determinasi

$\mathrm{Kd}=\mathrm{r}^{2} \times 100 \%$

$\mathrm{Kd}=0,633^{2} \times 100 \%$

$\mathrm{Kd}=40,08 \%$

c. Analisis Regresi Sederhana

$$
\begin{aligned}
& \mathrm{y}=\mathrm{a}+\mathrm{bx} \\
& b=\frac{n\left(\sum x y\right)-\sum x \sum y}{n\left(\sum x^{2}\right)-\left(\sum x\right)^{2}}
\end{aligned}
$$

$\mathrm{b}=$

$12\left(1,142538673+10^{19}\right)-(34.116 .200 .000)(334.896 .229)$

$12\left(1,163915102+10^{21}\right)-(34,116.200 .000)^{2}$

$1,371046408+10^{20}-1,142538673+10^{19}$

$1,396698122+10^{22}-1,163915102+10^{21}$

$$
\begin{aligned}
& \mathrm{b}=\frac{1,256792541+10^{20}}{1,280306612+10^{22}} \\
& \mathrm{~b}=0,0098 \\
& a=\frac{\sum y-b\left(\sum x\right)}{n} \\
& a=\frac{334.896 .229-0,0098(34.116 .200 .000)}{12} \\
& a=\frac{334.896 .229-334.338 .760}{12} \\
& a=\frac{557.469}{12}
\end{aligned}
$$

$$
a=46.455,75
$$

Persamaan Regresi $Y=46.455,75+0,0098 X$

d. Standar Estimasi

$$
\begin{aligned}
& S_{\theta}=\sqrt{\frac{\sum y^{2}-a \sum y-b \sum x y}{n-2}} \\
& S_{\theta}=\sqrt{\frac{\left(1,21554842+10^{17}\right)-46,455,75(334896229)-0,00098\left(1,142538673+10^{17}\right)}{n-2}} \\
& S_{\theta}=\sqrt{\frac{\left(1,21554842+10^{27}\right)-\left(1,5557855+10^{12}\right)-\left(1,1196879+10^{10}\right)}{10}} \\
& S_{\theta}=\sqrt{\frac{\left(1,211532862+10^{27}\right)-\left(1,1196879+10^{20}\right)}{10}} \\
& S_{\theta}=\sqrt{10,995,64+10^{20}}
\end{aligned}
$$

$\mathrm{Se}=10.486 .009,72$

e. Untuk menguji pengaruh Simpanan Berjangka terhadap Dana Baitul Maal sebagai Implementasi Coorporate Social Responsibility dilakukan perhitungan sebagai berikut :

$$
\begin{aligned}
t_{\text {hitung }} & =\sqrt[r]{\frac{(n-2)}{1-r^{2}}} \\
t_{\text {hitung }} & =\sqrt[0,6]{\frac{(12-2)}{1-0,633^{2}}} \\
t_{\text {hitung }} & =\sqrt[0,6]{16,666} \\
t_{\text {hitung }} & =2,449
\end{aligned}
$$

Untuk mengetahui hipotesis simpanan berjangka, $t_{\text {hitung }}$ telah diketahui yaitu sebesar 2,449 . Untuk $n=12$ dengan taraf kesalahan 5\%

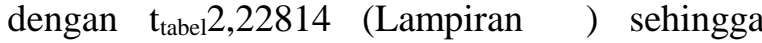
diperoleh hipotesis alternatif $(\mathrm{Ha})$ yaitu $\mathrm{t}_{\text {hitung }}=$ $2,449>t_{\text {tabel }} 2,22814$. Hal ini berarti simpanan berjangka berpengaruh terhadap dana Baitul Maal.

Koefisien determinasi untuk perhitungan simpanan berjangka adalah $0,633^{2}=0,40$. Ini berarti varian yang terjadi pada variabel dana Baitul Maal adalah 40,08\% ditentukan oleh varian yang ada pada Simpanan Berjangka sedangkan sisanya $60 \%$ ditentukan oleh faktor lain seperti donatur dan ziswaf pembiayaan.

Faktor lain yang menentukan besarnya dana Baitul Maal seperti pembiayaan di KJKS BMT Umat Sejahtera, produk simpanan lain, dan tidak kalah penting adalah para donatur tetap. Apabila dilakukan analisis data maka dapat diambil kesimpulan bahwa semakin lama waktu simpanan berjangka mengendap semakin banyak dana Baitul Maal yang dihimpun. Hal ini dikarenakan jumlah bagi hasil yang semakin besar dan berbanding lurus dengan partisipasi ziswaf simpanan berjangkanya. 


\section{KESIMPULAN DAN SARAN}

\section{Kesimpulan}

Berdasarkan dari hasil analisis data dan pembahasan pada bab sebelumnya, maka kesimpulan dari penelitian ini adalah sebagai berikut:

1. KJKS BMT Umat Sejahtera menerapkan prinsip simpanan berjangka mudharabah mutlaqah dimana KJKS BMT Umat Sejahtera mempunyai hak dan kebebasan dalam menginvestasikan dana simpanan berjangka dan pemilik dana akan mendapatkan pembayaran bagi hasil setiap bulan pada tanggal yang sama dengan tanggal pemasukan dana simpanan berjangka. Sedangkan nominal simpanan pada KJKS BMT Umat Sejahtera cukup besar yaitu mencapai Rp 4.471.250.000 pada tahun 2014 yang mengalami kenaikan $68,55 \%$ dari tahun sebelumnya sejumlah $\mathrm{Rp}$ 2.652.700.000.

2. Baitul Maal sebagai implementasi Corporate Social Responsibility di KJKS BMT Umat Sejahtera pada tahun 2014 telah dilaksanakan dengan berbagai kegiatan diantaranya Beastudi Dhuafa Berprestasi, Sembako Berkah, Pemberdayaan Ekonomi Umat, Program Tanggap Bencana, THK, Lebaran Ceria dll.

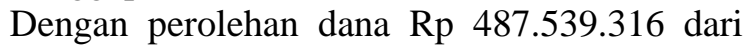
berbagai donatur dan berbagai ziswaf simpanan dan pembiayaan pada tahun 2014 telah ditasarufkan sebesar Rp 474.827.600 sehingga sisa saldo Rp 12.711.716.

3. Dari hasil perhitungan uji regresi linier sederhana dengan $\mathrm{n}=12$ dan tingkat kesalahan $5 \%$ diketahui $t_{\text {hitung }}>t_{\text {tabel }}$ yaitu 2,449 $>2,22814$. Ini berarti $\mathrm{Ha}$ diterima dan Ho ditolak berarti terdapat pengaruh antara simpanan berjangka terhadap dana Baitul Maal sebagai implementasi Corporate Social Responsibility di KJKS BMT Umat Sejahtera.

\section{Saran}

Berdasarkan dari kesimpulan di atas, maka rekomendasi dari penelitian ini adalah sebagai berikut:

1. Mengoptimalkan produk simpanan berjangka 6 bulan agar terdapat kenaikan yang sama besar dengan simpanan berjangka lain.

2. Untuk kegiatan Baitul Maal sebagai implementasi Coorporate Social Responsibility di KJKS BMT Umat Sejahtera akan lebih baik jika menetapkan mekanisme serta pemantauan secara berkala, jelas dan transparan sehingga masyarakat dapat memonitor kegiatan tersebut misalnya dengan melaporkan hasil kegiatan kepada steakholder setiap bulan.

3. Dari hasil perhitungan regresi linier sederhana yang dilakukan oleh penulis, $40 \%$ terdapat pengaruh simpanan berjangka terhadap dana Baitul Maal sedangkan $60 \%$ berasal dari faktor lain. Oleh sebab itu memaksimalkan simpanan berjangka merupakan salah satu kebijakan dan keputusan yang bagus dikarenakan semakin banyak simpanan berjangka semakin banyak pengendapan dan semakin tinggi assetnya, dan yang tidak kalah penting adalah kontribusi dana Baitul Maal sebagai implementasi Coorporate Social Responsibility semakin banyak.

4. Dengan berbagai keterbatasan peneliti dalam penelitian ini, untuk pengembangan penelitian selanjutnya, disarankan untuk menggunakan 2 metode penelitian agar hasil dari penelitian dapat dibandingkan dan lebih akurat.

\section{DAFTAR PUSTAKA}

\section{A. DOKUMEN}

KJKS BMT Umat Sejahtera.Laporan Keuangan Harian NSS April 2014.Kebumen.

\section{B. BUKU - BUKU ILMIAH}

Bambang Rudito \& Melia Famiola.2007.Etika Bisnis dan Tanggung Jawab Sosial Perusahaan.Bandung: RekayasaSains.

KJKS BMT Umat Sejahtera.Rapat Anggota Tahunan Tutup Buku Tahun 2014.Kebumen.

Perhimpunan BMT Indonesia.2014.Pedoman Akad Syariah.Jakarta.

Prof.Dr.Sugiyono.2012.Metode Penelitian Kombinasi.CV Alfabeta : Bandung.

Sam Ichwan.2006.Himpunan Fatwa Dewan Syariah Nasional.Ciputat.

Sinuor Yosephus.2010.Etika Bisnis Pendekatan Filsafat Moral terhadap Perilaku Pebisnis Kontemporer, Jakarta:Yayasan Pustaka Obor Indonesia.

Yusuf Wibisono.2007.Membedah Konsep dan Aplikasi CSR.Gresik : Fascho Publishing.

Ir.Adidarmawan.2011.Bank Islam.Jakarta:PT Ercontara Rajawali.

Ansori Ghofur.2009.Perbankan Syariah di Indonesia.Jogjakarta:Gajaah Mada University Pres.

\section{SUMBER INTERNET}

http://ilmuakuntansi.web.id/perbedaan-antarabunga-dan-bagi-hasil/ dikutip tanggal 02-102015 jam 13.51WIB 
